
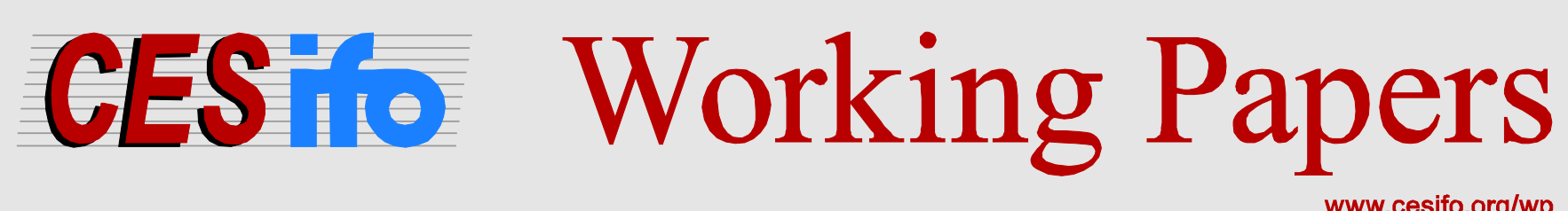

www.cesifo.org/wp

\title{
The U.S. Dollar Exchange Rate and the Demand for Oil
}

\author{
Selien De Schryder \\ Gert Peersman
}

\author{
CESIFO WORKING PAPER NO. 4126 \\ CATEGORY 10: ENERGY AND CLIMATE ECONOMICS \\ FEBRUARY 2013
}
An electronic version of the paper may be downloaded
- from the SSRN website:
- from the RePEc website:
- from the CESifo website:
wWw.SSRN.com
www.RePEc.org
www.CESifo-group.org/wp

\section{CESifo}




\title{
The U.S. Dollar Exchange Rate and the Demand for Oil
}

\begin{abstract}
Using recent advances in panel data estimation techniques, we find that an appreciation of the US dollar exchange rate leads to a significant decline in oil demand for a sample of 65 oilimporting countries. The estimated effect turns out to be much larger than the impact of a shift in the global crude oil price expressed in US dollar. Furthermore, the effect of the US dollar on oil demand tends to be declining over time and, for a subsample of OECD countries, stronger for an appreciation compared to a depreciation of the US dollar.
\end{abstract}

JEL-Code: C330, F310, Q410.

Keywords: oil demand, US dollar exchange rate, panel data, nonlinearities.

Selien De Schryder

Department of Financial Economics

Ghent University

9000 Gent / Belgium

selien.deschryder@ugent.be
Gert Peersman

Department of Financial Economics

Ghent University

9000 Gent / Belgium

gert.peersman@ugent.be

December 2012

We thank Julio Carrillo, Gerdie Everaert, Eric Monnet, Arnoud Stevens, Joris Wauters and participants at the Bank of England, CAMA and MMF Workshop on "Understanding Oil and Commodity Prices" and the European Central Bank and Norges Bank workshop "Monetary Policy and Commodity Prices" for useful comments and suggestions. We acknowledge financial support from the Research Foundation Flanders (FWO). All remaining errors are ours. 


\section{Introduction}

There is a growing consensus that global crude oil price fluctuations are mainly driven by changes in the demand for oil. Hamilton (2009) has for instance demonstrated that strong growth in world income was the primary cause of the oil price surge in 2007-08, whereas the subsequent dramatic collapse of oil prices was the result of the global economic downturn in the aftermath of the financial crisis. Furthermore, Peersman (2005), Kilian (2009), Peersman and Van Robays (2009), Lombardi and Van Robays (2011) and Kilian and Murphy (2012) disentangle different sources of oil price shocks within a structural vector autoregressive (SVAR) model, and find a dominant role for shocks at the demand side of the global crude oil market.

Surprisingly, the role of the US dollar exchange rate has so far been ignored in these empirical studies. In particular, since global oil prices are predominantly expressed in US dollars, a shift in the dollar exchange rate should affect the demand for crude oil in countries that do not use the US dollar for local transactions. When the US dollar exchange rate depreciates, oil becomes for instance less expensive for consumers in non-US dollar regions, boosting their demand for oil (Austvik 1987). The rise in oil demand outside the US should in turn influence global oil production and oil prices expressed in US dollar. In other words, changes in the US dollar exchange rate could be an important source of global oil demand fluctuations. This conjecture is supported by the data shown in Figure 1. The figure shows the evolution of the real effective US dollar exchange rate, together with respectively detrended global oil production (right panel) and the real price of crude oil expressed in US dollars (left panel). As can be seen in the figure, an appreciation (depreciation) of the dollar exchange rate is typically accompanied by a decline (rise) in both global oil prices and oil production, indicating a fall (rise) in global oil demand. The above mentioned studies, however, do not explicitly consider shifts in the US dollar exchange rate as a possible driver of global oil prices, production and consumption.

A similar argument could be made for several studies that exclusively focus on the analysis of the determinants of oil demand. In particular, Gately and Huntington (2002), Cooper (2003), Dargay, Gately and Huntington (2007), Narayan and Smyth (2007) and Dargay and Gately (2010) amongst others estimate oil demand functions for multiple countries. These studies consider oil demand as a positive function of income per capita and a negative function of its own price. For the latter, they typically use global crude oil 
prices expressed in US dollars. The influence of shifts in the US dollar exchange rate on oil demand is not taken into account in these studies, which could even bias the estimated income and price elasticities. Some studies (e.g., Griffin and Schulman 2005; Fawcett and Price 2012) do use local oil (gasoline) prices in the estimations, but do not distinguish between local oil price movements that are caused by global oil price shifts or by changes in the exchange rate. There is, however, no a priori reason to assume that the influence of both sources of oil price shifts on oil demand is the same.

In this paper, we formally examine the role of the US dollar exchange rate as a driver of oil demand in non-US dollar regions. Specifically, we estimate the determinants of oil consumption per capita for a panel of 65 oil-importing countries over the sample period 1971-2008. A panel data approach is commonly used in the literature on oil (energy) demand, as it allows to exploit both the cross-section and the time dimension of the data to identify the effects. We conduct panel estimations for respectively a sample of 23 OECD countries, 42 non-OECD countries and all 65 oil-importing countries. Besides real GDP per capita, we include global real crude oil prices expressed in US dollar, as well as the real effective US dollar exchange rate in the estimations. An explicit analysis of the role of the US dollar as a possible driver of oil consumption is a first contribution of the paper. ${ }^{1}$

A second contribution of the paper is methodological. In particular, most existing panel data studies on oil demand do not fully take into account the specific salient features of macro panel data sets such as heterogeneity of the coefficients, unit root behavior and crosscountry dependence, even though the neglect of these matters can result in misleading estimation outcomes. We apply recent advances in panel estimation techniques that are capable to handle these econometric issues. Specifically, we (i) take into account the cointegration relationships between the variables by estimating a panel error correction oil demand model, (ii) allow for cross-country heterogeneity of the coefficients which is present in the data, and (iii) correct for cross-sectional dependence in the error terms. The application of these econometric advances turns out to matter for some of the estimated coefficients.

\footnotetext{
${ }^{1}$ To our knowledge, the only empirical study which also considers the US dollar exchange rate as a possible determinant of oil demand is Askari and Krichene (2010). They estimate, however, a time series simultaneous equation model for (aggregate) world oil demand and supply between 1970 and 2008, whereas we estimate the impact of the US dollar exchange rate for a panel of 65 countries. In addition, they examine the effect of the exchange rate as part of a monetary policy channel affecting global oil prices, rather than an independent driver of oil demand.
} 
We find that an appreciation of the US dollar real effective exchange rate leads to a decline in oil consumption in non-US dollar regions. Strikingly, the short-run US dollar exchange rate elasticity of oil demand turns out to be much larger than the elasticity of oil demand with respect to fluctuations in the world price of crude oil expressed in US dollar. A back-of-the-envelope calculation furthermore suggests that shifts of the US dollar exchange rate are economically an important contributor to the volatility of the global price of crude oil expressed in US dollar, due to its influence on oil demand. These findings underline that the US dollar exchange rate should be taken into account in the analysis of global oil market dynamics and sources of oil price fluctuations.

This paper also highlights the existence of time variation and asymmetries in the reaction of oil demand to US dollar exchange rate changes, which can be considered as a third contribution. On the one hand, in line with Hughes, Knittel and Sperling (2008) and Baumeister and Peersman (2012), who show that the price elasticity of oil demand has declined considerably since the mid-eighties, we find a similar time shift in the response of oil demand to the dollar exchange rate. On the other hand, we find that oil consumption in OECD countries reacts asymmetrically to a strengthening or weakening US dollar, with a stronger reaction to an appreciation of the US dollar. This finding is consistent with Gately and Huntington (2002) and Huntington (2010), who document an asymmetric impact of rising versus falling oil prices on the demand for oil.

The remainder of this paper is organized as follows. In the next section, we describe the baseline empirical model for oil demand and discuss some econometric issues. Section 3 discusses the estimation and robustness of the results, while the economic relevance is assessed in section 4. Nonlinearities of the exchange rate effects are examined in section 5. Finally, section 6 concludes.

\section{Empirical oil demand model}

In this section, we describe the benchmark oil demand model that will be used in the estimations. Our sample contains 65 oil-importing countries and covers the period 19712008. ${ }^{2}$ Details of the data and a list of the countries can be found in Appendix A. Consider

\footnotetext{
${ }^{2}$ We do not consider oil-exporting countries since oil demand in these countries have been found to behave very differently. See for example Gately and Huntington (2005).
} 
the following general oil demand specification for country $i$ at time $t$ :

$$
\operatorname{dem}_{i t}=f\left(g d p_{i t}, \text { oilp }_{t}, \text { rer }_{t}, \operatorname{trend}_{t}, c_{i}\right)
$$

where $d e m_{i t}$ is total oil consumption per capita, $g d p_{i t}$ real income per capita, oilpt the global real US dollar crude oil price and rer $_{t}$ the real effective US dollar exchange rate, trend $_{t}$ a linear time trend and $c_{i}$ a country-specific constant. All variables are converted to natural logarithms, such that the model is of the constant elasticity form. The data are at annual frequency.

The existing empirical literature typically considers oil consumption, or energy consumption more generally, as a positive function of real income and a negative function of its own price (e.g., Dahl and Sterner 1991; Dahl 1993; Espey 1998; Gately and Huntington 2002; Cooper 2003; Griffin and Schulman 2005; Hughes et al. 2008; Lee and Lee 2010; Dargay and Gately 2010). In line with these studies, we include country-specific real GDP per capita in the general oil demand specification. Real GDP is assumed to represent the energy-using capital stock, such as buildings, equipment and vehicles (Dargay and Gately 2010).

As a measure for the own price of oil demand, most studies use the global price of crude oil expressed in US dollar (e.g., Gately and Huntington 2002; Cooper 2003; Dargay et al. 2007; Narayan and Smyth 2007; Dargay and Gately 2010). However, as we have discussed in the introduction, the global price of crude oil expressed in US dollar is not the only determinant of the price that consumers face in non-US dollar regions. In particular, fluctuations in the US dollar exchange rate should also be important for consumers in countries that do not use the US dollar as a currency for local transactions (Austvik 1987). Accordingly, we adopt the global real crude oil price expressed in US dollar, as well as the real US dollar effective exchange rate as two separate variables in our empirical oil demand model. ${ }^{3}$ We use the US dollar real effective exchange rate rather than real bilateral exchange rates in the benchmark estimations for three reasons. First, a multilateral weighted exchange rate reflects changes in the value of the US dollar itself, which is the variable of

\footnotetext{
${ }^{3}$ The choice to use global crude oil prices is in the existing literature often motivated by the lack of availability of individual country end-use oil price data, which would constrain the sample considerably (e.g., Gately and Huntington 2002). The use of global oil prices also avoids endogeneity problems of using local oil prices. In particular, the global oil price can be considered as exogenous for individual country's oil demand. Some studies (e.g. Griffin and Schulman 2005) ignore these problems and do use local oil (gasoline) prices for a limited set of countries.
} 
interest for the analysis of global oil market dynamics. Second, bilateral exchange rates (or domestic CPI) are not available for several countries over the whole sample period, which would significantly reduce the size of the dataset. Third, bilateral exchange rates suffer an endogeneity problem as the demand for oil of an individual country is expected to influence its own exchange rate. Given the limited weight of each individual country in the US trade basket, this is much less the case for the US dollar effective exchange rate. In section 3.2, we assess the robustness of the results for a specification with the bilateral exchange rates estimated for a subsample of countries using instrumental variables.

Microeconomic theory (e.g. Mas-Colell, Whinston and Green 2007) suggests that oil demand is also a function of the economy's structure, technology and the prices of substitutes. To capture the former two, all our estimations have a country-specific constant and a linear trend. Unfortunately, prices of substitutes are not available for our sample period. Griffin and Schulman (2005), however, report only weak substitution effects when they include the real price of substitute fuels in a demand model for petroleum products, and argue that omitting cross-price effects does not appreciably alter their results. ${ }^{4}$ Notice also that such effects are implicitly taken into account in our analysis since we correct for cross-sectional dependence in the estimations, as discussed in section 2.3.

\subsection{Panel unit root and cointegration tests}

To avoid spurious regression results, we first examine the time series properties of the variables. Since cross-section dependence (CD) tests (Pesaran 2004) on the residuals of Augmented Dickey Fuller (ADF) regressions indicate a significant degree of cross-section dependence for the country-specific variables $\left(d e m_{i t}\right.$ and $\left.g d p_{i t}\right)$, we employ the Panel Analysis of Non-stationarity in Idiosyncratic and Common components (PANIC) test proposed by Bai and Ng (2004) for both series. ${ }^{5}$ The number of common factors $(r)$

\footnotetext{
${ }^{4}$ Frankel (2006) argues that oil and other commodity price developments are influenced by interest rates. Specifically, when the interest rate declines, commodities become more attractive as an asset for investors. In addition, a lower interest rate stimulates overall demand, including the demand for oil. Notice, however, that this is not relevant for our analysis since we consider oil consumption (not inventories) at the LHS of the oil demand function, while real GDP is included at the RHS.

${ }^{5}$ Other panel unit root tests that also use a common factor representation of the data to allow for crosssection dependence (Moon and Perron 2004; Pesaran 2007) impose restrictions on the number of common factors and/or assume stationarity of the common factors. Given the results concerning the number and the stationarity properties of the common factors, these alternative tests are not used.
} 
is determined by the Bai and $\mathrm{Ng}(2002)$ criteria. $^{6}$ Table 1 shows that $r$ varies between one and four, depending on the variable and the criterion under consideration. Due to the non-stationarity of the common component, both series are, however, found to be non-stationary for all specifications.

Given that the global real crude oil price variable and the US dollar real effective exchange rate are observed common factors, we use standard ADF tests for both series. For global crude oil prices, the existence of a unit root cannot be rejected for a constant only, as well as a linear trend model. However, this is not the case for the US dollar real effective exchange rate, where the ADF test rejects non-stationarity of the series. This finding is at odds with the empirical purchasing power (PPP) literature, where standard univariate ADF tests typically fail to reject the null hypothesis. Engel (2000) shows that standard unit root tests may, however, be biased in favour of rejecting non-stationarity if the real exchange rate has a stationary and a non-stationary component. For this reason, and to ensure consistency with the other variables in the model, we continue to treat the US dollar real effective exchange rate as a non-stationary variable in the analysis.

In a second step, we test for cointegration amongst the variables using the panel error correction test (GUW test) of Gengenbach, Urbain and Westerlund (2008). The test is based on the significance of the error correction term in the panel error correction model (ECM). Compared to residual-based panel unit root tests, the GUW test has the advantage that it is not subject to the common factor critique and that it does not rely on a stepwise testing procedure (Kremers, Ericsson and Dolado 1992). ${ }^{7}$ Notice that the GUW test is however more restrictive than residual-based tests by imposing weak exogeneity on the country-specific regressors of the ECM and strong exogeneity on the common factors, whereas residual-based tests allow for full endogeneity. To take this restriction into account, we have also applied residual-based panel cointegration tests in the spirit of Banerjee and Carrion-i-Silvestre (2006) to check the robustness of the results. ${ }^{8}$ The results of the tests are shown in Table 2. The pooled GUW tests reject the null hypothesis of no error correction between $d e m_{i t}, g d p_{i t}$, oilpt and $r e r_{t}$ for the two models under

\footnotetext{
${ }^{6}$ We consider the IC1, IC2 and BIC3 criteria. The BIC3 criterion is more robust when there is cross correlation in the idiosyncratic errors (Bai and $\mathrm{Ng} 2002$ ).

${ }^{7}$ The common factor critique applies to residual-based panel cointegration tests as they rely on residual rather than structural dynamics (Gengenbach et al. 2008).

${ }^{8}$ The approach we take to examine the robustness of the GUW test results is the following: we apply the continuously-updated and bias-corrected (CupBC) estimator of Bai et al. (2009) to the long-run cointegration equation and we test the (de-factored) residuals for a unit root using the PANIC test procedure.
} 
consideration. The alternative residual-based cointegration tests confirm this result. As a consequence, we can safely conclude that $d e m_{i t}, g d p_{i t}$, oilpt $p_{t}$ and $r e r_{t}$ are cointegrated at the panel level.

\subsection{Panel error correction oil demand model}

Having established cointegration between the variables, we can formulate our general oil demand specification as a panel ECM:

$$
\begin{aligned}
\Delta \operatorname{dem}_{i t}= & \alpha_{i}+\tau_{i} * \operatorname{trend}_{t}+\lambda_{i} * \operatorname{dem}_{i, t-1}+\beta_{i}^{l} * \operatorname{oilp}_{t-1}+\gamma_{i}^{l} * g d p_{i, t-1}+\theta_{i}^{l} * \operatorname{rer}_{t-1}+ \\
& \beta_{i} * \Delta \operatorname{oilp}_{t}+\gamma_{i} * \Delta g d p_{i t}+\theta_{i} * \Delta \operatorname{rer}_{t}+\varepsilon_{i t}
\end{aligned}
$$

Equation (2) is the baseline empirical specification for the panel ECMs that will be estimated in this paper. ${ }^{9}$ Gately and Huntington (2002) and Griffin and Schulman (2005) are most closely related to our study as they both estimate single equation total oil demand models for a panel of multiple countries with a moderate time dimension. ${ }^{10}$ Before we estimate the panel ECM, it is important to discuss two econometric issues which are typically disregarded in the existing oil demand literature, namely slope heterogeneity and cross-sectional error dependence.

\subsection{Econometric issues}

In order to obtain reliable estimates, we need to consider two important econometric features of macro panel data. The first one concerns heterogeneity in the slope coefficients. Heterogeneity in the slope coefficients renders the standard FE estimator biased as the latter assumes homogeneity in the slope coefficients. Gately and Huntington (2002) and

\footnotetext{
${ }^{9}$ The lag order of the dynamic adjustment process is imposed to be 0 for all variables for reasons of parsimony. Experiments with more lags, however, do not alter the results.

${ }^{10}$ Gately and Huntington (2002) have a sample of 93 countries over 1971-1997. Griffin and Schulman (2005) have data on 16 OECD countries over 1961-1999. Griffin and Schulman (2005) include retail oil prices instead of the global oil price in their model, which makes their estimation outcomes less adequate to serve as a benchmark. Both works consider the standard Fixed Effects (FE) estimator. Notice that this FE estimator suffers small T problems in dynamic panels (Arellano and Bond 1991). Given that the time dimension of our sample is moderately large, we assume that this bias is not relevant for our purposes. Nickell (1981) namely shows that the upward bias on the error correction term becomes insignificant when $\mathrm{T} \rightarrow \infty$.
} 
Griffin and Schulman (2005) amongst others apply the FE estimator without considering this restrictive assumption. Although Gately and Huntington (2002) notice a substantial heterogeneity within non-OECD countries and split their sample in different groups of countries (OECD countries versus oil exporters, income growers and other non-OECD countries), they do not take the possibility of heterogeneity within groups into account. Similarly, Griffin and Schulman (2005), who only analyze a sample of OECD countries, do not assess the homogeneity assumption across OECD countries. Given the cross-country differences in economic structures, the assumption of homogenous slope coefficients is questionable. The homogeneity assumption could, however, easily be tested by means of a Hausman or likelihood-ratio test. Indeed, the application of both tests consistently reveals that the homogeneity restriction on the slope coefficients is not valid, even not for a subsample of OECD countries (see Table 3). The FE estimator is hence biased and the estimated coefficients potentially misleading. Accordingly, we use the Mean Group (MG) estimator in the analysis, which offers a consistent alternative as the MG estimator does not impose homogeneity.

The second important feature of macro panel data estimations relates to error crosssection dependence. In particular, the results of standard FE and MG estimators are inefficient and have biased standard errors when the observed explanatory variables are correlated with unobserved common factors (Pesaran 2006). For oil demand, this is likely the case. Country-specific income, the real price of crude oil, as well as the US dollar real effective exchange rate could for instance be driven by a common global business cycle. The existing empirical oil demand studies do nevertheless not correct for the potentially far-reaching consequences of cross-sectional dependence. The presence of cross-section dependence in the error terms of dynamic models could be tested with the CD test of Pesaran (2004). Applying the CD test to our panel error correction oil demand model shows that there is a significant degree of cross-sectional correlation in the error terms for both the FE and MG estimators (see Table 3), which confirms our concern about possibly biased results of existing panel studies that do not take into account the dependence.

The common correlated effects (CCE) estimators of Pesaran (2006), notably the CCE pooled (CCEP) and mean group (CCEMG) estimators, are typically used to eliminate cross-sectional dependence. In particular, the CCE estimators use the cross-section averages of the dependent and explanatory variables as observable proxies for a linear combination of unobserved common factors. This approach asymptotically eliminates strong 
and weak forms of cross-section dependence and is consistent for both stationary and nonstationary common factors (Kapetanios, Pesaran and Yamagata 2010). A non-standard feature of our specification, however, is the presence of observed common factors as explanatory variables, namely the global real price of oil $\left(\right.$ oilp $\left._{t}\right)$ and the real effective US dollar exchange rate $\left(\right.$ rer $\left._{t}\right)$, which makes the standard application of the CCE approach of Pesaran (2006) unattractive. ${ }^{11}$ We therefore opted to apply the Bai and Ng (2004) PANIC decomposition to the residuals of the model in order to estimate the common components in the residuals. In the spirit of Bai, Kao and $\mathrm{Ng}$ (2009), the estimated common factor(s) is (are) then in a second step included in the model to get consistent estimates. This procedure allows us to remove, or at least significantly reduce, the common factors that are present in the residuals of the first step. ${ }^{12}$ By including the estimated common components of the residuals of the MG regression as a proxy for omitted common variables in the model, we indeed notice a substantial decline of the cross-sectional correlation in the residuals (Table 3 , bottom row).

In sum, in contrast to the existing empirical evidence on the demand for oil, we do not only examine the role of the US dollar exchange rate for the demand for oil, we also apply panel estimators that take both heterogeneity of the coefficients and cross-sectional dependence into account.

\section{Empirical results}

\subsection{Panel estimations}

Table 3 summarizes the estimation results of the panel error correction model as described in section 2. In order to compare with the existing evidence, we report the results for respectively OECD countries, non-OECD countries and the total sample of oil-importing countries. ${ }^{13}$ For each sample, we show the results for the FE, MG and MG estimator

\footnotetext{
${ }^{11}$ Adding only the cross-section averages of the real income per capita variables $\left(\overline{g d p}_{t-1}\right.$ and $\left.\overline{\Delta g d p}_{t}\right)$ as additional regressors to the model does result in a lower degree of cross-sectional dependence, but the reduction is only marginal.

${ }^{12}$ The drawback of this approach, however, is that the estimation error from the first step carries over to the subsequent steps.

${ }^{13}$ Given the panel data nature and similar sample of countries, we consider Griffin and Schulman (2005) and the results of Gately and Huntington (2002) without the incorporation of the asymmetric price reactions as the benchmarks.
} 
adjusted for cross-sectional dependence (MG_Ft), which should allow us to evaluate the relevance of the econometric features discussed in section 2.3 for the estimation results.

Income elasticity We consistently find a significant positive effect of real GDP on the demand for oil. The short-run income elasticity in OECD countries (0.568) is larger than the 0.401 found by Griffin and Schulman (2005), and definitely larger than the zero income elasticity of Gately and Huntington (2002), Holtz-Eakin and Selden (1995) and Schmalensee, Stoker and Judson (1998). On the other hand, Dargay et al. (2007) and Dargay and Gately (2010) find an even higher income elasticity in the short-run, i.e. respectively 0.88 and 0.80 . Furthermore, the estimated impact of economic activity on the demand for oil is slightly higher for non-OECD countries (0.639) and the total sample of countries (0.614). A lower income elasticity in more developed countries is in line with the existing literature (e.g. Gately and Huntington 2002).

The econometric issues that we discussed in section 2.3 seem to matter for the magnitudes of the estimates. Specifically, the short-run income elasticity for OECD countries rises from 0.568 to 0.672 if we do not take into account cross-sectional dependence in the error terms, and even to 0.741 if we also do not allow for cross-country heterogeneity in the coefficients. Interestingly, exactly the opposite happens for non-OECD countries, i.e., the short-run income elasticity declines from 0.639 to respectively 0.615 and 0.537 when there is not allowed for correlation and heterogeneity across countries. In other words, the bias resulting from the use of a FE estimator is relevant and works in both directions.

Moving to the long-run income elasticity, there is one caveat that needs to be discussed first. In particular, for some countries in the panel, there seems to be no or only very weak cointegration present in the data. This implies that the estimated error-correction terms for a few countries are very close to zero, which in turn inflates the long-run coefficients for these countries considerably because there has to be divided by the near-zero error correction term to calculate the long-run coefficients. As a consequence, the values of the mean group and the standard errors of the long-run panel coefficients are distorted. To take this feature into account, we also report the median of the estimated long-run parameters in the tables and interpret them with caution. ${ }^{14}$ The median long-run income elasticity turns out to be $0.674,0.885$ and 0.775 for respectively OECD, non-OECD and all 65 oil-importing countries, which is within the range of existing studies.

\footnotetext{
${ }^{14}$ Note that a near-zero error correction term does not influence the short-run elasticities.
} 
(Global) oil price elasticity There are numerous papers that estimate the effects of a shift in (global) crude oil prices on the demand for oil. Most studies report a relatively low, or even an insignificant (e.g. Askari and Krichene 2010) short-run price elasticity of oil demand, which is important because a low oil price elasticity implies that any disruption in oil supply has a considerable impact on the price of oil. As can be seen in Table 3, we find a significant negative (short-run) effect of a change in the global price of crude oil expressed in US dollars on the demand for oil in OECD-countries (-0.051), non-OECD countries (-0.026) and the overall sample of countries that do not use the US dollar for local transactions (-0.035). These values are in line with the low elasticities found in the existing multi-country panel literature. Gately and Huntington (2002) find for instance a short-run price elasticity of -0.054 for OECD countries and -0.029 for non-OECD countries. ${ }^{15}$ Notice also that the estimated values for the FE, MG and MG estimator adjusted for cross-section correlation turn out to be very similar for the OECD sample. This is, however, not the case for the panel of non-OECD countries. In particular, the effect of global crude oil prices on oil demand is only significant when we allow for cross-country heterogeneity in the slope coefficients and take into account cross-section dependence in the errors terms. Hence, the econometric issues that we have discussed in section 2.3 do also matter for the estimated oil price elasticity.

We further find a stronger response of oil demand to a global oil price shift in the long run. The estimated median long-run price elasticities are respectively -0.150 and -0.104 for OECD and non-OECD countries. As a benchmark, Gately and Huntington (2002) find for OECD and non-OECD countries a value of respectively -0.59 and -0.16 with a FE estimator.

Exchange rate elasticity Our results reveal that there is a considerable effect of the US dollar exchange rate on oil demand in the rest of the world, despite the fact that we control for country-specific real GDP and global crude oil prices, which supports the conjecture that the US dollar exchange rate is an important driver of oil demand. More specifically, when the US dollar real effective exchange rate appreciates by 1 percent, there is a shortrun decline in oil demand of 0.204 percent in OECD countries. Strikingly, the estimated elasticity is four times bigger than the global crude oil price elasticity expressed in US

\footnotetext{
${ }^{15}$ Larger magnitudes for the short-run oil price elasticity are found by Bodenstein and Guerrieri (2011) within an estimated DSGE model and by Kilian and Murphy (2012) and Baumeister and Peersman (2012a) within a structural VAR framework.
} 
dollar. The equality of the short-run price and real exchange rate elasticity is rejected at the panel level. ${ }^{16}$ The negative effect of the exchange rate on oil demand in OECD countries increases even further to 0.385 in the long run (median estimate), a value which is still more than twice the (median) long-run elasticity of the global oil price determined in US dollar of -0.150 .

The short-run impact of the US dollar exchange rate on oil demand in non-OECD countries is much lower $(-0.051)$ and statistically insignificant. Notice that the latter is not the case for the FE estimator that is typically used in the oil demand literature, which confirms that the features of macro panel data sets are relevant for the interpretation of the results. A possible explanation for the relative large standard error of the exchange rate elasticity coefficient for the sample of non-OECD countries could be the fact that some of these countries had varying exchange rate regimes or experienced exchange rate crises during the sample period. Interestingly, despite not being statistically significant, the magnitude of the estimated exchange rate elasticity for non-OECD countries is again considerably larger (i.e. double) than the estimated global oil price elasticity.

Finally, the US dollar real effective exchange rate elasticity for the total sample of 65 oil-importing countries is -0.105 and significant, which is three times larger than the global oil price elasticity expressed in US dollar for the same sample of countries. In sum, the US dollar exchange rate matters for oil demand in countries which do not use the dollar as a currency for local transactions. A weakening of the US dollar boosts oil demand in these individual countries and therefore it possibly shifts the global oil demand curve, impacting global oil prices and production. In the next subsection, we assess the robustness of this novel finding.

\subsection{Some robustness checks}

In this section, we first evaluate the robustness of the results for possible endogeneity problems between oil demand, the US dollar exchange rate and the global price of crude oil. It is a standard assumption in existing multi-country oil demand studies that the demand for oil of an individual country does not influence the global price of crude oil on

\footnotetext{
${ }^{16}$ Askari and Krichene (2010) estimate a time series simultaneous equation model for global oil demand and supply using quarterly data over a similar sample period (1970-2008), and also find an impact of the US dollar (nominal) exchange rate on oil demand which is stronger in magnitude than the effect of the price of oil, but both elasticities turn out to be statistically insignificant in their analysis.
} 
impact. This assumption is even made when the US, which has an average share in world oil consumption of $27 \%$, is part of the sample. In our benchmark estimations (excluding the US), we have made the same assumption for both global oil prices and the US dollar real effective exchange rate. However, if oil demand of the individual countries does affect the global price of crude oil or the US dollar effective exchange rate on impact, the estimated elasticities could be biased. Given the fact that oil is predominantly traded in US dollar and our sample contains important trading partners of the US, fluctuations in the demand for oil in these countries could for instance influence the effective US dollar exchange rate. Remark that, if such a bias is present, the true exchange rate elasticity of oil demand is probably even larger than the one we have reported above. An increase in a country's oil demand raises for instance its demand for US dollars, leading to an appreciation of the dollar, which could reduce the estimated (negative) elasticity. A similar reasoning applies to the global price of crude oil.

To check the robustness of the results, we have therefore re-estimated the baseline panel error correction oil demand models with instrumental variables (IV). In particular, we instrument the first difference of the global price of crude oil and the US dollar real effective exchange rate in equation 2 by the first difference and the level of the US federal funds rate and the exogenous common variables in the model (i.e., the lagged levels of the global price of crude oil and the US dollar real effective exchange rate, a constant and a trend). The results are shown in the left part of Table 4.

The income elasticity coefficients are comparable to the benchmark results reported in section 3.1. Also the estimated oil price elasticities are only minorly affected. More importantly in the context of the present study, there is still a significant effect of the US dollar exchange rate on the demand for oil. The estimated elasticities turn out to be even larger than the benchmark results, pointing to a possible downward bias of the benchmark results due to the endogeneity of the US dollar exchange rate. The (short-run) exchange rate elasticity is now also statistically significant for non-OECD countries. We obviously have to be careful when interpreting the magnitudes of the coefficients given the loss of power of two-stage regressions with instrumental variables. ${ }^{17}$ Nevertheless, these results confirm the significance of the US dollar exchange rate for the consumption of crude oil

\footnotetext{
${ }^{17}$ This is also reflected in the relatively large standard errors and cross-section error correlation coefficients, as well as the median long-run exchange rate elasticities in some of the results reported in Table 4 .
} 
in non-US regions.

As another robustness check, we have also estimated a specification with bilateral real exchange rates instead of the US real effective exchange rate. While the effective US dollar exchange rate reflects changes in the value of the US dollar, i.e. the currency unit which matters for the global oil market, bilateral exchange rates capture more the effects on the local oil price that consumers have to pay in each individual country. We again opt for IV estimations, with the same instruments as described above. ${ }^{18}$ The right part of Table 4 shows the results. Notice that the sample size for the different groups of countries is now smaller due to the non-availibility of bilateral exchange rate and/or domestic CPI data for some countries over the time period under consideration (see Appendix A). This change of sample size should thus be taken into account when comparing the results, especially for non-OECD countries.

The short-run coefficients are comparable to the benchmark results for the OECD sample, in particular the income and (bilateral) exchange rate elasticities. The oil price elasticity, however, turns out to be not significantly different from zero anymore in OECD countries. On the other hand, for non-OECD countries, the income and price elasticity estimates appear to be lower in magnitude compared to the benchmark estimates, whereas the exchange rate elasticity is now larger. Overall, we can conclude from the robustness analysis that the US dollar exchange rate continues to matter for the consumption of crude oil in non-US regions.

\section{Global elasticities and economic relevance}

In this section, we evaluate the relevance of our findings for global oil market dynamics. More precisely, we first calculate global elasticities, which could serve as a benchmark for empirical studies that estimate global oil demand functions based on aggregate oil market data. In a next step, we perform a back-of-the-envelope calculation in order to assess how important fluctuations in the US dollar exchange rate could be for global crude oil production and prices.

\footnotetext{
${ }^{18}$ Note that a possible endogeneity problem between the bilateral US dollar exchange rate and the country-specific demand for oil is much more serious compared to the estimations with the effective exchange rate. For the global crude oil price, we continue to use the lagged level of the real effective US dollar exchange rate as one of the instruments.
} 
Global elasticities The estimated elasticities reported in section 3 are the unweighted averages of the individual country coefficients. However, average elasticities are not very useful for the analysis of the global oil market, which is essentially a weighted average of all individual countries in the world. To have a better idea about the relevance of the US dollar exchange rate for global oil demand, we have also derived weighted MG estimates of the panel error correction oil demand model, where the weights of the country-specific coefficients are determined by the share of the respective country in total oil demand over the sample. Accordingly, countries with a larger share in global oil demand have more weight such that the resulting MG estimates better represent global elasticities. Given that our sample represents 59 percent of non-US global oil demand, we could safely assume that the weighted estimates are a good approximation for global (non-US) oil demand.

Table 5 shows the results for the total sample of 65 countries, as well as the unweighted benchmark estimates. The global short-run income and oil price elasticities are both still statistically significant. ${ }^{19}$ Interestingly, the global (weighted) income elasticity is lower than its unweighted counterpart, whereas the global price elasticity of crude oil demand is somewhat larger. In particular, the estimated global income and oil price elasticity are respectively 0.484 and -0.045 in the short run. The magnitude of the global price elasticity of oil demand can, for instance, be useful for the SVAR literature that imposes boundary restrictions on the short-run price elasticity of oil demand to identify different types of structural innovations in the oil market (e.g. Juvenal and Petrella 2012; Kilian and Murphy 2012).

The influence of the US dollar exchange rate on (non-US) oil demand is also still significantly negative. Moreover, the weighted elasticity $(-0.168)$ is much larger than the simple mean of the individual country elasticities (-0.105). Finally, given the fact that the US represents on average 27 percent of global oil demand over the sample, these findings imply that a 1 percent appreciation of the US dollar leads to a decline in global oil demand by $-0.168 *(1-0.27)=-0.123$ percent.

A back-of-the-envelope calculation To have a better idea about the relevance of US dollar exchange rate fluctuations for global oil market dynamics, we have also performed a simple back-of-the-envelope calculation. Given its simplicity, the exact numbers should however be interpreted with caution. The calculation does, for instance, not take into

\footnotetext{
${ }^{19}$ Notice that the weighting does not affect median long-run coefficients.
} 
account endogenous dynamics. It should nevertheless give an idea about the importance of the US dollar for the oil market.

Based on our estimation results, consider the following simplified short-run oil demand function for the global oil market:

$$
\Delta q_{\text {oil }}=-0.045 \Delta p_{\text {oil }}-0.123 \Delta \operatorname{rer}_{U S}
$$

where $q_{o i l}, p_{\text {oil }}$ and $\operatorname{rer}_{U S}$ are respectively global crude oil demand, the global real price of crude oil and the real effective US dollar exchange rate. Furthermore, according to Kilian and Murphy's (2012) reading of the literature, the upper bound on the short-run price elasticity of oil supply is 0.025 , which gives us the following simplified short-run global crude oil supply function:

$$
\Delta q_{\text {oil }}<0.025 \Delta p_{\text {oil }}
$$

Solving this model delivers the following effects of a shift in the US dollar exchange rate on oil prices and production:

$$
\begin{aligned}
\left|\Delta p_{\text {oil }}\right| & >1.757\left|\Delta \operatorname{rer}_{U S}\right| \\
\left|\Delta q_{\text {oil }}\right| & >0.044\left|\Delta \operatorname{rer}_{U S}\right|
\end{aligned}
$$

As a benchmark, the monthly average of $\left|\Delta r e r_{U S}\right|$ in the data is for instance 1.16 percent. According to our simple back-of-the-envelope calculation, this corresponds to an average shift in global oil prices by more than 2.04 percent. Given the fact that the monthly average of $\left|\Delta p_{\text {oil }}\right|$ in the data is 4.76 percent, the relevance of US dollar exchange rate fluctuations for global oil price dynamics is considerable. Due to the very low oil supply elasticity, this is less the case for oil production. In particular, the monthly average of $\left|\Delta q_{\text {oil }}\right|$ in the data is 1.08 percent, whereas exchange rate fluctuations could only explain about 0.05 percent according to our simple calculations.

\section{US dollar exchange rate and nonlinearities of oil demand}

Having established a significant impact of shifts in the US dollar exchange rate on oil demand, in this section, we examine whether the effects are (non)linear. Specifically, previous work has found a fall in the short-run price elasticity of oil demand over time (e.g. Hughes et al. 2008; Baumeister and Peersman 2012), and a stronger effect of oil 
price increases on the demand for oil compared to oil price decreases (e.g. Gately and Huntington 2002). Hence, it would be interesting to see whether similar nonlinearities also exist for the effects of the US dollar exchange rate.

\subsection{Time variation of exchange rate elasticity}

There is a consensus in the literature that the short-run price elasticity of oil demand has declined since the second half of the 1980s. The exact reasons for the fall in the price elasticity are, however, not yet very well understood. ${ }^{20}$ Some studies attribute the decline to structural changes in the (real) economy. In particular, they argue that a reduction in the use of oil input per unit of output helps to account for the decline of the short-run price elasticity of oil demand. The fall of oil intensity in aggregate economic activity, in turn, is attributed to the fact that industries switched away from oil to alternative source of energy, developed more energy-efficient technologies and improved energy conservation in the aftermath of the oil price spikes of the 1970s (e.g. Hughes et al. 2008; Dargay and Gately 2010). Another structural change put forward in the literature is a shift of oil consumption towards sectors which are characterized by a low own-price elasticity of demand due to a lack of substitutes, such as the transportation sector (e.g. Dargay and Gately 2010; Ramey and Vine 2011). All these explanations for a fall in the oil price elasticity should basically account for the US dollar exchange rate elasticity of oil demand as well.

On the other hand, Baumeister and Peersman (2012) argue that also structural changes in the oil market itself could be a reason for the declined price elasticity of oil demand over time. Baumeister and Peersman (2012) argue that high capacity utilization rates in crude oil production since the second half of the eighties increases the willingness of oil consumers to pay an insurance premium for potential oil scarcity, resulting in a higher share of less elastic speculative or precautionary buying in the oil market. If this structural change in the oil market is the dominant reason for the observed time variation of the price elasticity of oil demand, there is no reason to expect that the demand for oil is subject to a fall in its reaction to US dollar exchange rate changes over time.

In order to examine whether the US dollar exchange rate elasticity has also decreased over time, we add the US dollar real effective exchange rate interacted with a simple linear

\footnotetext{
${ }^{20}$ For a more detailed overview of possible reasons for the decline over time, we refer to Baumeister and Peersman (2012).
} 
time trend as an additional variable to the baseline panel ECM:

$$
\begin{aligned}
\Delta \operatorname{dem}_{i t}= & \alpha_{i}+\tau_{i} * \operatorname{trend}_{t}+\lambda_{i} * \operatorname{dem}_{i, t-1}+\beta_{i}^{l} * \operatorname{oilp}_{t-1}+\gamma_{i}^{l} * g d p_{i, t-1}+\theta_{i}^{l} * \operatorname{rer}_{t-1}+ \\
& \beta_{i} * \Delta \operatorname{oilp}_{t}+\gamma_{i} * \Delta g d p_{i t}+\theta_{i} * \Delta \operatorname{rer}_{t}+\delta_{i} * \Delta \operatorname{rer}_{t} * \operatorname{trend}_{t}+\varepsilon_{i t}
\end{aligned}
$$

The results of these estimations are shown in Table 6 . The first three columns of the table reveal that the impact of the US dollar real effective exchange rate became indeed smaller over time. In particular, the exchange rate elasticity has over time decreased on average by 0.013 per year in OECD countries, by 0.012 in non-OECD countries, and by 0.012 for the total sample of 65 countries. The estimated interaction coefficients are statistically significant for the OECD and total sample of countries, but not for the nonOECD countries (the p-value for non-OECD countries is 0.163 ). In sum, the results denote the presence of a declining short-run exchange rate elasticity over time, similar to the evidence on the short-run price elasticity documented in the existing literature.

\subsection{Appreciations versus depreciations}

Another popular asymmetry in the price elasticity of oil demand documented in the literature is a stronger effect of oil price increases relative to a decline in oil prices. The basic idea is that higher prices induce more investment in energy-efficient equipment and retrofitting of existing capital, such as switching to energy-efficient cars and greater insulation. When prices fall, however, there is no switch back to less-efficient capital, although there could be more intensive usage, e.g., driving more miles and adjusting thermostats to more comfortable levels (Griffin and Schulman 2005). Gately and Huntington (2002) allow for a different reaction of oil demand to price increases that result in a new historical maximum price, to price increases back to the previous maximum and to price decreases. They find that oil demand responds differently to the different price shifts, with the largest (negative) effect of price increases that result in new maximum values.

We examine whether there exists a similar asymmetry in the reaction of oil demand to a US dollar appreciation versus a depreciation by adding to the benchmark panel ECM the interaction between the real effective exchange rate with a dummy variable that equals 
1 if there is an appreciation of the US dollar effective exchange rate and 0 otherwise: ${ }^{21}$

$$
\begin{aligned}
\Delta \text { dem }_{i t}= & \alpha_{i}+\tau_{i} * \operatorname{trend}_{t}+\lambda_{i} * \operatorname{dem}_{i, t-1}+\beta_{i}^{l} * \operatorname{oilp}_{t-1}+\gamma_{i}^{l} * g d p_{i, t-1}+\theta_{i}^{l} * \operatorname{rer}_{t-1}+ \\
& \beta_{i} * \Delta \operatorname{oilp}_{t}+\gamma_{i} * \Delta g d p_{i t}+\theta_{i} * \Delta \operatorname{rer}_{t}+\delta_{i} * \Delta \operatorname{rer}_{t} * d u m m y+\varepsilon_{i t}
\end{aligned}
$$

The results are shown in the middle part of Table 6. The interaction term is only significant for the sample of OECD countries. The existence of an asymmetric reaction to a strenghtening versus a weakening US dollar is thus confined to this group. The estimated degree of asymmetry is notably large, i.e., a depreciating US dollar does not invoke a significant oil demand reaction in OECD countries, whereas an appreciating US dollar leads to a considerable decline in oil products demand. The results further reveal that there is no (significant) asymmetry present in non-OECD countries and the total sample of countries. The estimated coefficients have even the opposite (expected) sign.

Griffin and Schulman (2005) argue that the results of Gately and Huntington (2002) primarily reflect energy-saving technology rather than price asymmetry. More specifically, they show that the evidence for oil price asymmetry vanishes once time effects that serve as proxies for technological change are incorporated in the model of Gately and Huntington (2002). To take this into account, we have also verified whether the existence of an asymmetric response of oil demand to an appreciating versus depreciating US dollar exchange rate still holds once we control for time variation in the exchange rate elasticity. ${ }^{22}$ In particular, we have re-estimated the panel ECM allowing for both forms of nonlinearities. As such, we could also check whether the decline of the exchange rate elasticity over time, which we have documented in section 5.1, still holds after controlling for an appreciating versus depreciating US dollar. Given that the US dollar experienced a persistent depreciation after its peak level at the beginning of 1985, it is not unlikely that both nonlinearities interfere. These results can be found in the last three columns of Table 6. Again, the interaction term of the dummy variable and the real effective exchange rate regressor is only significant for the OECD sample. Also the trend interaction term coefficients remain

\footnotetext{
${ }^{21}$ Given the validity of the PPP-hypothesis for exchange rates in the long run, we do not distinguish between appreciations of the exchange rate to a new historical maximum and an increase back to the previous maximum.

${ }^{22}$ Note that we take the hypothesis of Griffin and Schulman (2005) one step further, as we already control for a common time trend and other common unobserved factors in the panel ECM model. So, we verify whether asymmetries in the exchange rate elasticity still exist, even after controlling for more general time variation and other common variables.
} 
more or less the same. The results are thus robust for this extension, i.e., both linearities are still present in the data.

\section{Conclusions}

In this paper, we have examined the role of the US dollar exchange rate for the demand for oil in non-US dollar regions by using recent advances in panel data estimation techniques. In particular, we have estimated a panel error correction oil demand model allowing for cross-country heterogeneity in the slope coefficients and taking into account cross-country common unobserved variables. The results show that an appreciation of the US dollar exchange rate robustly leads to a decline in the demand for oil in countries that do not use the US dollar for local transactions, which supports the premise of a significant exchange rate channel underlying oil demand dynamics. Strikingly, a 1 percent shift in the real US dollar exchange rate seems to have a much stronger effect on oil demand than a 1 percent shift in the global real crude oil price determined in US dollar. The reason for this stronger effect is beyond the scope of this paper, but could be a promising avenue for future research. Potential directions are the lower volatility of the US dollar exchange rate compared to global oil prices, different hedging activities in the oil and exchange rate market or the fact that the real exchange rate is mean reverting.

In addition, we have highlighted the existence of nonlinearities in the exchange rate elasticity of oil demand. The estimations reveal that the impact of US dollar exchange rate shifts on the demand for oil has become smaller over time. Moreover, oil consumption reacts asymmetrically to a rising or falling US dollar, with a larger reaction to an appreciation of the US dollar. 


\section{A Data}

\section{Sources and construction of the data:}

- Total oil demand (1000 barrels per day): IEA, Oil Information database

- Total midyear population (number of persons): US Census Bureau, International database

- Global real crude oil price (US dollars per barrel): EIA, Refiner acquisition cost of imported crude oil

- Real gross domestic product per capita.: Penn World Tables 7.0, PPP Converted GDP Per Capita (Chain Series), 2005 constant prices

- Real US dollar effective exchange rate: BIS, real effective exchange rate index (CPIbased), Narrow Index

- Monthly Crude oil and NGL production for Figure 1 (1000 barrels per day): IEA, Oil Information database

- Individual country nominal exchange rates [ER] (national currency unit to US $\$$, period average) : IMF, IFS database

- Consumer prices [CPI] (indices, 2005=100): IMF, IFS database

-> Total oil demand per capita [DEM] (1000 barrels per day, per 1000 persons) = Total Oil demand/ Total population*1000

-> Real international crude oil price [POIL]: International nominal crude oil price/ CPIust*100

-> real exchanges rates $[\mathrm{bRER}]=$ ERit $*$ CPIust $/$ CPIit

The dataset is balanced for 65 oil-importing countries over the sample period 19712008. All variables are converted to natural logarithms, such that the models are of the constant elasticity form.

OECD sample (23 countries): Australia, Austria, Belgium, Denmark, Finland, France, Germany, Greece, Hungary, Iceland, Ireland, Italy, Japan, Korea, Luxembourg, Netherlands, New Zealand, Poland, Portugal, Spain, Sweden, Switzerland and Turkey 
Non-OECD sample (42 countries) : Bangladesh, Benin, Bolivia, Brazil, Bulgaria, Chile, China, Costa Rica, Cote d'Ivoire, Cyprus, Dominican Republic, El Salvador, Ethiopia, Ghana, Guatemala, Haiti, Honduras, Hong Kong, India, Israel, Jamaica, Jordan, Kenya, Malta, Morocco, Mozambique, Nicaragua, Pakistan, Paraguay, Peru, Philippines, Romania, Senegal, Singapore, South Africa, Sri Lanka, Sudan, Tanzania United Republic, Thailand, Uruguay, Zambia and Zimbabwe

The following countries have been excluded from the analysis because of being a net oil-exporting country, i.e. countries for which the production of crude oil has been larger than total oil demand for at least 25 years: Canada, Mexico, Norway, United Kingdom, Algeria, Angola, Argentina, Bahrain, Cameroon, Colombia, Congo, Congo Democratic Republic, Ecuador, Egypt, Gabon, Indonesia, Iran, Iraq, Kuwait, Malaysia, Nigeria, Oman, Qatar, Saudi Arabia, Syrian Arab Republic, Tuniasia, United Arab Emirates and Venezuela

When the model includes the bilateral real US dollar exchange rate instead of the real effective US dollar exchange rate index, the total sample reduces to 44 countries (20 OECD and 24 non-OECD countries) due to missing data for the bilateral nominal exchange rates and/or consumer price indices for the entire time period under consideration.

-> Missing OECD: Hungary, Poland, Turkey

-> Missing non-OECD: Bangladesh, Benin, Bolivia, Brazil, Bulgaria, Chile, China, Ghana, Hong Kong, Israel, Mozambique, Nicaragua, Peru, Romania, Sudan, Uruguay, Zambia, Zimbabwe 


\section{References}

[1] Arellano, M. and S. Bond. (1991) "Some tests of specification for panel data: Monte Carlo evidence and an application to employment equations", The Review of Economic Studies, vol 58(2), $277-297$.

[2] Askari, H. and N. Krichene (2010) "An oil demand and supply model incorporating monetary policy", Energy, vol 35(5), 2013-2021.

[3] Austvik, O.G. (1987) "Oil prices and the dollar dilemma", OPEC Review, 11, 399412.

[4] Bai, J., C. Kao and S. Ng (2009) "Panel cointegration with global stochastic trends", Journal of Econometrics , vol 149, 82-99.

[5] Bai, J. and S. Ng (2002) "Determining the number of factors in approximate factor models", Econometrica , vol 70, 191-221.

[6] Bai, J. and S. Ng (2004) "A panic attack on unit roots and cointegration", Econometrica, vol 72, 1127-1177.

[7] Banerjee, A., and L.J., Carrion-i-Silvestre (2006) "Cointegration in panel data with breaks and cross-section dependence", ECB Working Paper Series, 591.

[8] Baumeister, C. and G. Peersman (2012a) "The role of time-varying price elasticities in accounting for volatility changes in the crude oil market", Journal of Applied Econometrics, forthcoming.

[9] Baumeister, C. and G. Peersman (2012b), "Time-Varying Effects of Oil Supply Shocks on the US Economy", Working Papers 12-2, Bank of Canada.

[10] Choi, I. (2001) "Unit Root Tests for Panel Data", Journal of International Money and Finance, vol 20, 249-272.

[11] Cooper, J.C.B. (2003) "Price elasticity of demand for crude oil: Estimates for 23 countries", OPEC Review, 27, 1-8.

[12] Dahl, C.A. (1993) "A survey of oil demand elasticities for developing countries", OPEC Review, 17, 399-419. 
[13] Dahl, C. and T. Sterner (1991) "Analyzing Gasoline Demand Elasticities: A survey" Energy Economics, vol 3(13), 203-210.

[14] Dargay, J.M. and D. Gately (2010) "World oil demand's shift toward faster growing and less price-responsive products and regions", Energy Policy, vol. 38, 6261-6277.

[15] Dargay, J.M., Gately, D., and H.G., Huntington (2007) "Price and Income Responsiveness of World Oil Demand, by Product", Energy Modeling Forum, Occasional working paper EMF OP 61.

[16] Dickey, D.A., and W.A. Fuller (1979) "Distribution of the Estimators for Autoregressive Time Series with a Unit Root", Journal of the American Statistical Association, $74,427-431$.

[17] Engel, C. (2000) "Long-run PPP may not hold after all", Journal of International Economics vol 51 (2), 243-273.

[18] Espey, M. (1998) "Gasoline Demand Revisited: An International Meta-Analysis of Elasticities." Energy Economics, vol 20(3), 273-295.

[19] Fawcett, N. and S. Price (2012) "World oil demand in a cross-country panel", Working paper.

[20] Gately, D. and H.G. Huntington (2002) "The asymmetric effects of changes in price and income on energy and oil demand", The Energy Journal, vol 23(1), 19-55.

[21] Gengenbach, C., J.-P. Urbain, and J. Westerlund (2008) "Panel error correction testing with global stochastic trends", METEOR Research Memorandum RM/08/051, Maastricht University.

[22] Griffin, J.M. and C.T. Schulman (2005) "Price asymmetry in energy demand models: a proxy for energy-saving technical change?", The Energy Journal, vol 26(2), 1-21.

[23] Hamilton, J.D. (2009) "Causes and consequences of the oil shock of 2007-08", NBER Working Papers 15002.

[24] Holtz-Eakin, D. and T.M, Selden (1995) "Stoking the fires? CO2 emissions and economic growth," Journal of Public Economics, vol 57(1),85-101. 
[25] Hughes, J.E., C.R. Knittel and D. Sperling (2008) "Evidence of a shift in the short-run price elasticity of gasoline demand", The Energy Journal, vol 29(1), p 93-114.

[26] Huntington, H.G. (2010) "Oil demand and technical progress", Applied Economics Letters, vol. 17(18), p 1747-1751.

[27] Juvenal, L. and I., Petrella (2012) "Speculation in the oil market," Economic Synopses, Federal Reserve Bank of St. Louis.

[28] Kapetanios, G., M.H. Pesaran, and T. Yamagata (2011) "Panels With Nonstationary Multifactor Error Structures", Journal of Econometrics, vol 160(2), 326-348.

[29] Kilian, L. (2009) "Not all oil price shocks are alike: disentangling demand and supply shocks in the crude oil market", American Economic Review, 99, 1053-1069.

[30] Kilian, L. and D. Murphy (2012) "Why Agnostic Sign Restrictions Are Not Enough: Understanding the Dynamics of Oil Market VAR Models", Journal of the European Economic Association, forthcoming.

[31] Kremers, J. J. M., N. R. Ericsson, and J. J. Dolado (1992) "The power of cointegration tests", Oxford Bulletin of Economics and Statistics, vol 54, 325-348.

[32] Lee, C.-C. and J-D., Lee (2010) "A Panel Data Analysis of the Demand for Total Energy and Electricity in OECD Countries", Energy Journal, vol 31(1), 1-23.

[33] Lombardi, M. and I. Van Robays (2011) "Do financial investors destabilize the oil price?", Working Paper Series European Central Bank, 1346.

[34] Maddala, G. S., and S. Wu (1999) "A Comparative Study of Unit Root Tests with Panel Data and a New Simple Test", Oxford Bulletin of Economics and Statistics, Special Issue, 631-652.

[35] Mas-Colell, A., Whinston,M.D. and J.R. Green (2007) "Microeconomic Theory", Oxford University Press: New York, NY.

[36] Moon, H. R. and B. Perron (2004) "Testing for a unit root in panels with dynamic factors", Journal of Econometrics, vol 122, 81-126.

[37] Narayan, P.K. and R. Smyth (2007) "A panel cointegration analysis of the demand for oil in the Middle East", Energy Policy, vol 12, 6258-6265. 
[38] Nickell, S. (1981) "Biases in Dynamic Models with Fixed Effects", Econometrica, vol $49(6), 1417-1426$.

[39] Peersman, G. (2005) "What caused the early millennium slowdown? Evidence based on vector autoregressions", Journal of Applied Econometrics, 20, 185-207.

[40] Peersman, G. and I. Van Robays (2009) "Oil and the Euro Area Economy", Economic Policy, vol 24(60), 603-651.

[41] Pesaran, M.H. (2004) "General diagnostic tests for cross section dependence in panels", University of Cambridge, Faculty of Economics, Cambridge Working Papers in Economics No. 0435

[42] Pesaran, M.H. (2006) "Estimation and inference in large heterogeneous panels with a multi-factor error structure", Econometrica, vol 74, 967-1012.

[43] Pesaran, M.H. (2007) "A simple panel unit root test in the presence of cross section dependence", Journal of Applied Econometrics, vol 22, 365-312.

[44] Ramey, V.A., and D. J. Vine (2011) "Oil, Automobiles, and the U.S. Economy: How Much Have Things Really Changed?," NBER Macroeconomics Annual 2010, vol 25, 333-367.

[45] Schmalensee, R., Stoker, T.M. and R.A., Judson (1998) "World Carbon Dioxide Emissions: 1950-2050," The Review of Economics and Statistics, vol. 80(1), 15-27.

[46] Stock, J.H., and M.W. Watson (1988) "Testing for Common Trends", Journal of the American Statistical Association, 83, 1097-1107. 
Figure 1 - The US dollar exchange rate, oil prices and oil production
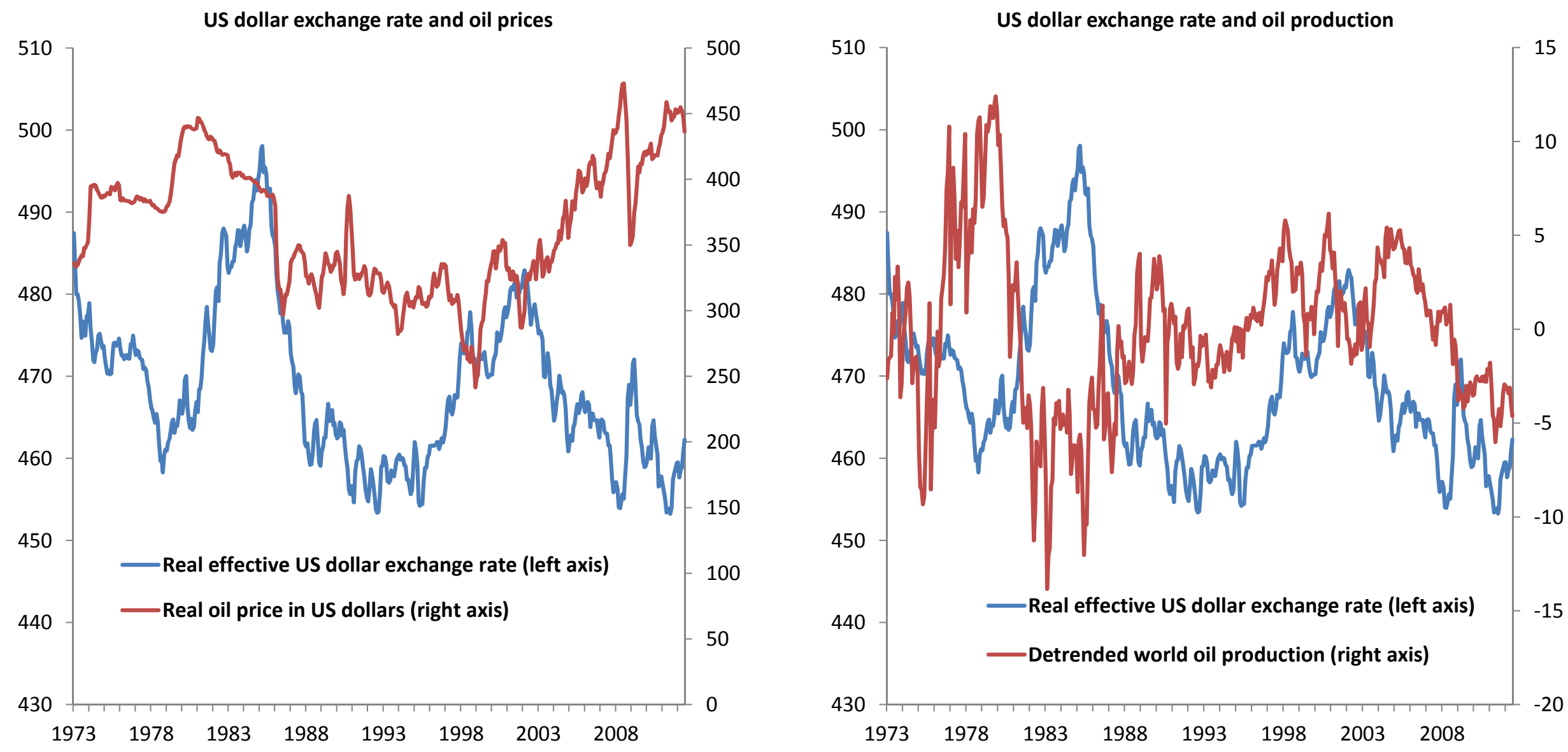

Note: values for real effective US dollar exchange rate and real oil prices in US dollars are $100 * \log$, oil production is percentage points deviation from quadratic trend 


\begin{tabular}{|c|c|c|c|c|}
\hline \multicolumn{5}{|c|}{ Table 1: results PANIC tests, total sample } \\
\hline & \multicolumn{4}{|c|}{ Estimated number of common factors ( $r$ ) } \\
\hline & DEMit & \multicolumn{3}{|c|}{ GDPit } \\
\hline IC1 & 4 & \multicolumn{3}{|l|}{2} \\
\hline IC2 & 4 & \multicolumn{3}{|l|}{1} \\
\hline \multirow[t]{4}{*}{$\mathrm{BIC3}$} & 2 & 1 & & \\
\hline & \multicolumn{4}{|c|}{ intercept only model } \\
\hline & \multicolumn{2}{|c|}{ DEMit } & \multicolumn{2}{|c|}{ GDPit } \\
\hline & $r=2$ & $r=4$ & $r=1$ & $r=2$ \\
\hline MW & 113,95 & 100,54 & $177.77^{* * *}$ & $217.35^{* * *}$ \\
\hline Choi & $-1,25$ & $-1,827$ & $2.96 * * *$ & $5.42 * * *$ \\
\hline ADFf & - & - & 1,33 & - \\
\hline MQc & $-0,93$ & $-0,18$ & - & $-0,18$ \\
\hline \multirow[t]{4}{*}{ MQf } & $-1,58$ & $-0,64$ & - & $-0,34$ \\
\hline & \multicolumn{4}{|c|}{ linear trend model } \\
\hline & \multicolumn{2}{|c|}{ DEMit } & \multicolumn{2}{|c|}{ GDPit } \\
\hline & $r=2$ & $r=4$ & $r=1$ & $r=2$ \\
\hline MW & $163.70^{* *}$ & 117,91 & 130,25 & 149,75 \\
\hline Choi & $2.09 * *$ & $-0,75$ & 0,02 & 1,22 \\
\hline ADFf & - & - & 0,18 & - \\
\hline MQc & $-6,09$ & $-4,8$ & - & $-3,34$ \\
\hline \multirow[t]{3}{*}{ MQf } & $-7,12$ & $-6,43$ & - & $-3,16$ \\
\hline & \multicolumn{4}{|c|}{ ADF test common observed variables } \\
\hline & intercep & model & linear $\mathrm{tr}$ & model \\
\hline OILPt & \multicolumn{2}{|c|}{$-1,25$} & \multicolumn{2}{|c|}{$-0,47$} \\
\hline RERt & \multicolumn{2}{|c|}{$-3.26 * *$} & \multicolumn{2}{|c|}{$-3.72 * *$} \\
\hline
\end{tabular}

\begin{tabular}{|c|c|c|c|}
\hline \multicolumn{4}{|c|}{ "GUW test } \\
\hline & Model 1 & Model 2 & Model 3 \\
\hline$\tau^{*} \alpha i$ & $-1,67$ & $-2.50^{*}$ & $-3.21 * * *$ \\
\hline$\omega^{*} \_i$ & $25.37 * * *$ & $28.69 * * *$ & $31.88 * * *$ \\
\hline \multicolumn{4}{|c|}{$\begin{array}{ll}\text { PANIC test on CupBC residuals } \\
\end{array}$} \\
\hline & & intercept only model & linear trend model \\
\hline & $\mathrm{W}$ & $276.79 * * *$ & 151,02 \\
\hline & noi & $9.10 * * *$ & $1.304 *$ \\
\hline
\end{tabular}

GUW test (Gengenbach, Urbain and Westerlund, 2008): pooled tests for no error correction Number of lags: determined by Akaike Information Criterion (AIC)

$\tau^{*} \_\alpha i=$ average of truncated version of the individual $t$-test statistics of no error correction $\omega^{*} \_i=$ average of truncated version of the individual Wald test statistics of no error correction Model $1=$ model with no deterministic terms

Model $2=$ model with unrestricted constant

Model $3=$ model with unrestricted constant and trend

PANIC test on CupBC residuals:

First step: Continously-updated bias-correcting (CupBC) estimator (Bai et al, 2009) on static long-run specification

Second step: PANIC test (Bai and Ng, 2004) on idiosyncratic part of residuals of first step regression

$\rightarrow$ remark: p-value $\mathrm{MW}$ panel unit root test in linear trend model $=0.1002$

PANIC test (Bai and $\mathrm{Ng}, 2004$ ):

Number of common factor determined by IC1, IC2 and BIC3 criteria (Bai and Ng, 2002)

Number of lags in both model specifications: determined by Bai and $\mathrm{Ng}(2004)$ rule: $4[\min [\mathrm{N}, \mathrm{T}] / 100]^{\wedge / 4}$

$\mathrm{MW}=$ Maddala and Wu (1999) pooled unit root test statistic on idiosyncratic term

Choi $=$ Choi (2001) pooled unit root test statistic on idiosyncratic term

ADFf $=$ Augmented Dickey Fuller (ADF) test (Dickey and Fuller, 1979) on estimated common factor if $r=1$

MQc/MQf = Modified variants of Stock and Watson's (1988) Qf and Qc statistics to determine

the number of factors spanning the non-stationary space of the common term

Augmented Dickey Fuller (ADF) test on observed common factors:

Lag order determined by Schwarz Bayesian Criterion (SBC)

$* * * / * * *$ : respectively refers to significance on the $1 / 5 / 10 \%$ level 


\begin{tabular}{|c|c|c|c|c|c|c|c|c|c|}
\hline \multicolumn{10}{|c|}{ Table 3: baseline model } \\
\hline & \multicolumn{3}{|c|}{ OECD } & \multicolumn{3}{|c|}{$\begin{array}{r}\text { non-OECD } \\
\end{array}$} & \multicolumn{3}{|c|}{ TOTAL } \\
\hline & $\mathrm{FE}$ & MG & MG_Ft & $\mathrm{FE}$ & MG & MG_Ft & $\mathrm{FE}$ & MG & MG_Ft \\
\hline \multirow[t]{2}{*}{ gdp } & $0.741^{* * *}$ & $0.672^{* * *}$ & $0.568^{* * *}$ & $0.537^{* * *}$ & $0.615^{* * *}$ & $0.639 * * *$ & $0.560^{* * *}$ & $0.635^{* * *}$ & $0.614^{* * *}$ \\
\hline & (0.094) & $(0.073)$ & $(0.073)$ & $(0.110)$ & $(0.113)$ & (0.119) & $(0.097)$ & $(0.077)$ & $(0.081)$ \\
\hline \multirow[t]{2}{*}{ oilp } & $-0.045^{* * *}$ & $-0.049 * * *$ & $-0.051 * * *$ & -0.013 & -0.018 & $-0.026 * *$ & $-0.023 * *$ & $-0.029 * * *$ & $-0.035 * * *$ \\
\hline & $(0.009)$ & $(0.007)$ & $(0.007)$ & $(0.014)$ & $(0.014)$ & $(0.012)$ & $(0.010)$ & (0.009) & $(0.008)$ \\
\hline \multirow[t]{2}{*}{ rer } & $-0.156^{* * *}$ & $-0.144^{* * *}$ & $-0.204^{* * *}$ & $-0.101^{*}$ & -0.072 & -0.051 & $-0.119 * * *$ & $-0.098 * * *$ & $-0.105^{* *}$ \\
\hline & $(0.037)$ & $(0.033)$ & $(0.040)$ & (0.059) & $(0.055)$ & $(0.068)$ & $(0.038)$ & $(0.037)$ & $(0.047)$ \\
\hline \multirow[t]{3}{*}{ trend } & $-0.003 * * *$ & -0.002 & -0.001 & -0.000 & 0.001 & -0.002 & $-0.001^{* * *}$ & -0.000 & -0.000 \\
\hline & $(0.000)$ & $(0.002)$ & $(0.002)$ & $(0.001)$ & $(0.002)$ & $(0.004)$ & $(0.000)$ & $(0.002)$ & $(0.002)$ \\
\hline & \multicolumn{9}{|c|}{ long-run coefficients } \\
\hline \multirow[t]{2}{*}{$\mathrm{EC}$} & $-0.125^{* * *}$ & $-0.261 * * *$ & $-0.196 * * *$ & $-0.252 * * *$ & $-0.429 * * *$ & $-0.395 * * *$ & $-0.233 * * *$ & $-0.370 * * *$ & $-0.324 * * *$ \\
\hline & $(0.045)$ & $(0.040)$ & $(0.046)$ & (0.094) & $(0.036)$ & $(0.035)$ & $(0.001)$ & $(0.029)$ & $(0.030)$ \\
\hline \multirow[t]{2}{*}{ gdp } & 1.331 & -11.110 & -2.825 & 0.793* & 0.343 & 6.263 & $0.845^{* *}$ & -3.709 & 3.047 \\
\hline & (1.021) & (10.929) & (3.985) & $(0.452)$ & $(0.430)$ & (5.517) & $(0.419)$ & $(3.882)$ & $(3.850)$ \\
\hline \multirow[t]{2}{*}{ oilp } & $-0.242 *$ & $-0.394^{* *}$ & -0.421 & -0.130 & -0.057 & 0.399 & $-0.143^{*}$ & $-0.176^{* *}$ & 0.109 \\
\hline & $(0.134)$ & (0.181) & (0.295) & $(0.085)$ & $(0.087)$ & $(.513)$ & $(0.074)$ & $(0.087)$ & (0.349) \\
\hline \multirow[t]{3}{*}{ rer } & -0.453 & -3.338 & -1.014 & -0.079 & -0.204 & -4.456 & -0.162 & -1.313 & -3.238 \\
\hline & $(0.373)$ & $(2.692)$ & $(0.819)$ & $(0.238)$ & $(0.183)$ & (4.055) & $(0.178)$ & (0.964) & (2.633) \\
\hline & \multicolumn{9}{|c|}{ median long-run coefficients } \\
\hline gdp & - & 0.495 & 0.674 & - & 0.847 & 0.885 & - & 0.781 & 0.775 \\
\hline oilp & - & -0.139 & -0.150 & - & -0.090 & -0.104 & - & -0.125 & -0.126 \\
\hline \multirow[t]{2}{*}{ rer } & - & -0.420 & -0.385 & - & -0.324 & -0.324 & - & -0.342 & -0.325 \\
\hline & \multicolumn{9}{|c|}{ Hausman test } \\
\hline \multirow[t]{2}{*}{ statistic } & & $87.04^{* * *}$ & & & $19.65^{* * *}$ & & & $47.88^{* * *}$ & \\
\hline & \multicolumn{9}{|c|}{ Likelihood ratio test } \\
\hline \multirow[t]{2}{*}{ statistic } & & $197.49 * * *$ & & & $393.18^{* * *}$ & & & $614.53^{* * *}$ & \\
\hline & \multicolumn{9}{|c|}{ Cross-section Dependence test } \\
\hline statistic & $12.44^{* * *}$ & $10.29 * * *$ & $1.99 * *$ & $8.74^{* * *}$ & $5.38 * * *$ & $4.43^{* * *}$ & $21.24 * * *$ & $11.59^{* * *}$ & $6.66^{* * *}$ \\
\hline$\rho$ & 0.129 & 0.106 & 0.021 & 0.049 & 0.030 & 0.025 & 0.077 & 0.042 & 0.024 \\
\hline
\end{tabular}

$\mathrm{FE}=$ Fixed Effects estimator

$M G=$ Mean Group estimator

MG_Ft= Mean Group estimator adjusted for cross-sectional dependence

$\rho=$ average pair-wise correlation coefficient of residuals 


\begin{tabular}{|c|c|c|c|c|c|c|}
\hline \multicolumn{7}{|c|}{ Table 4: robustness checks, MG_Ft } \\
\hline & \multicolumn{3}{|c|}{ Real effective US \$ exchange rate } & \multicolumn{3}{|c|}{ Real bilateral US \$ exchange rates } \\
\hline & OECD ( $N=23)$ & non-OECD ( $\mathrm{N}=44)$ & TOTAL $(\mathrm{N}=65)$ & OECD (N=20) & non-OECD ( $\mathrm{N}=24)$ & TOTAL $(\mathrm{N}=44)$ \\
\hline \multirow[t]{2}{*}{ gdp } & $0.589 * * *$ & $0.557^{* * *}$ & $0.523 * * *$ & $0.617^{* * *}$ & 0.394 & $0.495^{* * *}$ \\
\hline & $(0.078)$ & $(0.121)$ & $(0.082)$ & $(0.235)$ & $(0.284)$ & $(0.187)$ \\
\hline \multirow[t]{2}{*}{ oilp } & $-0.038^{*}$ & -0.018 & $-0.030 * * *$ & -0.027 & -0.014 & -0.020 \\
\hline & $(0.021)$ & $(0.034)$ & $(0.008)$ & $(0.045)$ & $(0.055)$ & $(0.036)$ \\
\hline \multirow[t]{3}{*}{ rer / brer } & $-0.595 * * *$ & $-0.400^{* *}$ & $-0.556 * * *$ & $-0.251^{*}$ & $-0.651^{*}$ & $-0.469 * *$ \\
\hline & $(0.105)$ & $(0.133)$ & $(0.130)$ & $(0.131)$ & $(0.342)$ & $(0.196)$ \\
\hline & \multicolumn{6}{|c|}{ long-run coefficients } \\
\hline \multirow[t]{2}{*}{ EC } & $-0.291 * * *$ & $-0.385 * * *$ & $-0.352^{* * *}$ & $-0.295^{* * *}$ & $-0.340 * * *$ & $-0.320 * * *$ \\
\hline & $(0.030)$ & $(0.035)$ & $(0.025)$ & $(0.030)$ & $(0.032)$ & $(0.022)$ \\
\hline \multirow[t]{2}{*}{ gdp } & 0.763 & 5.958 & 4.120 & $0.699 * *$ & $0.806^{* *}$ & $0.758^{* * *}$ \\
\hline & $(0210)$ & $(4.935)$ & (3.191) & $(0.301)$ & $(0.380)$ & $(0.246)$ \\
\hline \multirow[t]{2}{*}{ oilp } & $-0.076 * * *$ & 0.667 & 0.404 & $-0.195^{*}$ & -0.071 & -0.127 \\
\hline & $(0.025)$ & $(0.841)$ & $(0.526)$ & $0.113)$ & $(0.138)$ & $(0.0 .091)$ \\
\hline \multirow[t]{3}{*}{ rer / brer } & $-0.815^{* * *}$ & -3.596 & -2.612 & $3.346^{* *}$ & 3.806 & $3.597^{* *}$ \\
\hline & $(0.174)$ & (3.119) & $(2.015)$ & $(1.435)$ & $(2.709)$ & $(1.599)$ \\
\hline & \multicolumn{6}{|c|}{ median long-run coefficients } \\
\hline gdp & 0.732 & 0.867 & 0.842 & 0.560 & 0.855 & 0.769 \\
\hline oilp & -0.066 & -0.091 & -0.071 & -0.105 & -0.079 & -0.100 \\
\hline \multirow[t]{2}{*}{ rer / brer } & -0.559 & -0.434 & -0.535 & 2.362 & 1.623 & 1.768 \\
\hline & \multicolumn{6}{|c|}{ Cross-section Dependence test } \\
\hline$\rho$ & 0,056 & 0,039 & 0,022 & 0,174 & 0,048 & 0,003 \\
\hline
\end{tabular}




\begin{tabular}{|c|c|c|}
\hline \multicolumn{3}{|c|}{ Table 5: baseline model, MG_Ft } \\
\hline & \multicolumn{2}{|c|}{$\begin{array}{c}\text { TOTAL } \\
\end{array}$} \\
\hline & UNWEIGHTED & WEIGTHED \\
\hline gdp & $\begin{array}{c}0.614^{* * *} \\
(0.081)\end{array}$ & $\begin{array}{c}0.484^{* * *} \\
(0.164)\end{array}$ \\
\hline oilp & $\begin{array}{c}-0.035^{* * *} \\
(0.008)\end{array}$ & $\begin{array}{c}-0.045^{* * *} \\
(0.015)\end{array}$ \\
\hline rer & $\begin{array}{c}-0.105^{* *} \\
(0.047)\end{array}$ & $\begin{array}{c}-0.168^{* *} \\
(0.067)\end{array}$ \\
\hline \multirow[t]{2}{*}{ trend } & $\begin{array}{l}-0.000 \\
(0.001)\end{array}$ & $\begin{array}{l}-0.000 \\
(0.002)\end{array}$ \\
\hline & \multicolumn{2}{|c|}{ long-run coefficients } \\
\hline $\mathrm{EC}$ & $\begin{array}{c}-0.324^{* * *} \\
(0.030)\end{array}$ & $\begin{array}{c}-0.209 * * * \\
(0.078)\end{array}$ \\
\hline $\operatorname{gdp}$ & $\begin{array}{c}3.047 \\
(3.850)\end{array}$ & $\begin{array}{l}-4.791 \\
(5.470)\end{array}$ \\
\hline oilp & $\begin{array}{c}0.109 \\
(0.349)\end{array}$ & $\begin{array}{l}-0.490 \\
(0.469)\end{array}$ \\
\hline \multirow[t]{2}{*}{ rer } & $\begin{array}{l}-3.238 \\
(2.633)\end{array}$ & $\begin{array}{l}-1.785 \\
(1.389)\end{array}$ \\
\hline & \multicolumn{2}{|c|}{ median long-run coefficients } \\
\hline $\operatorname{gdp}$ & \multicolumn{2}{|c|}{0.775} \\
\hline oilp & \multicolumn{2}{|c|}{-0.126} \\
\hline rer & \multicolumn{2}{|c|}{-0.325} \\
\hline
\end{tabular}




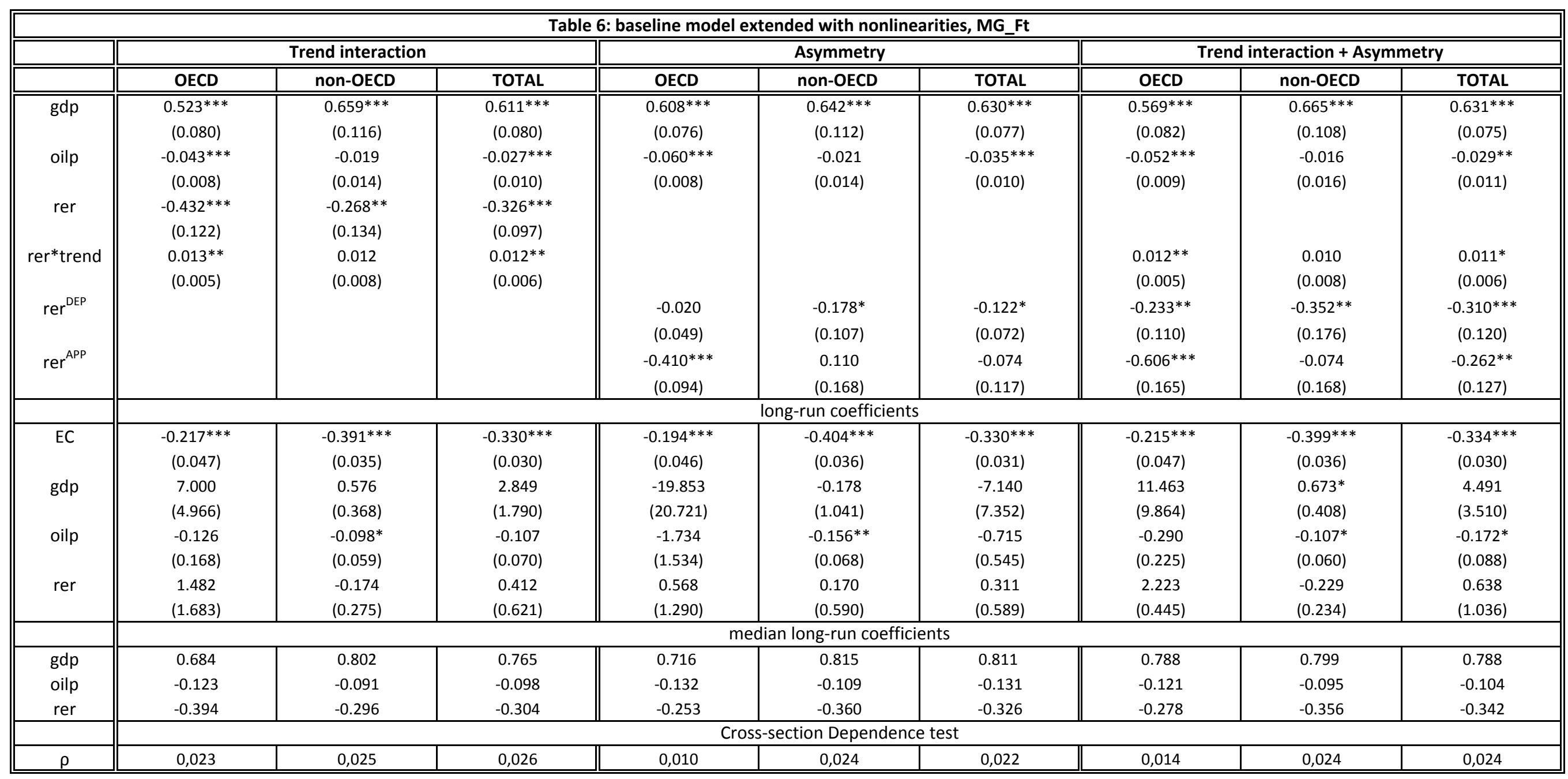

$\operatorname{rer}^{\mathrm{DEP}} / \mathrm{rer}^{\mathrm{APP}}$ : respectively refer to the short-run rer elasticity coefficients of a depreciating/appreciating (effective) US dollar 